\title{
Copper (II) ions removal from aqueous solution using bentonite treated with ammonium chloride
}

\author{
Boukerroui Abdelhamid ${ }^{1}$, Ali Ourari ${ }^{2}$, Mohand Said Ouali ${ }^{3}$ \\ ${ }^{1}$ LTMGP Laboratory, Department of chemistry Faculty of exacts sciences, university of Bejaia Algeria \\ ${ }^{2}$ LEIMCR Laboratory, Department of chemistry Faculty of Science and Technology University of Setif Algeria \\ ${ }^{3}$ LVM Laboratory, Department of chemistry Faculty of Science and Technology University of Mostaganem, Algeria
}

Email address:

Hamid_602001@yahoo.fr (B. Abdelhamid),alourari@yahoo.fr (A. Ourari),ouali@univ-mosta.dz (M. Said Ouali)

To cite this article:

Boukerroui Abdelhamid, Ali Ourari, Mohand Said Ouali. Copper (II) Ions Removal From Aqueous Solution Using Bentonite Treated with Ammonium Chloride, American Journal of Physical Chemistry. Vol. 1, No. 1, 2012, pp. 1-10. doi: 10.11648/j.ajpc.20120101.11

\begin{abstract}
A raw bentonite, obtained from Maghnia (Western Algerian) was impregnated into 1M ammonium chloride solution and thermally treated in a furnace at $200{ }^{\circ} \mathrm{C}$ during one hour. This treatment has improved its removal capacity of copper from aqueous solutions to about $30 \%$. The performances of the copper adsorption of this new material, after its physicochemical treatment, were evaluated by quantitative analysis on the copper remaining in the solution. The interface phenomena of bentonite- $\mathrm{Cu} 2+$ aqueous solution adheres to the Langmuir and Freundlich models. The adsorption energy, calculated by using Dubinin-Radushkevich equation, has proved that the removal of copper with this clay material is an ion exchange process. Nevertheless, the thermal treatment of this clay has inhibited the temperature effect on the retention of copper ions. Thus, the kinetic law governing the copper adsorption described here is following a second order model.
\end{abstract}

Keywords: Bentonite Activation, Ammonium Chloride, Removal Of Copper (II)

\section{Introduction}

Heavy metals are toxic substances present in the nature with tolerable quantities, but their accumulation due to the diverse rejections of agricultural and industrial activities has became a real threat to the environment. In order to treat the contaminated effluents of these inorganic pollutants, traditional physicochemical methods are, generally, used such as activated carbon molecular sieves, reverse osmosis, ion exchanging resin and electrodeposition have been applied. However, several difficulties which are essentially associated with the bad control of technology, availability and high cost of the methods. This situation has motivated some researchers to investigate other alternatives oriented to the use of natural materials as adsorbent that can eliminate toxic substance from aqueous solutions [1-4].

Among recent published works of this subject, the removal of copper (II) ions from the liquid rejections has attracted the attention in the literature [5-7]. The use of bentonites in the elimination of this pollutant appears to be the most studied methods [2,3]. The montmorillonite, which is considered as the main component of bentonites of Maghnia [8], is a clay of smectites family that have good adsorption properties due to its specific surface and cation exchange capacity (CEC) [9]. Many works have been devoted to improve above mentioned properties, for instance, [10-13]. The improvement can be brought by a chemical or thermal activation of this material. The activation technique by chemical ways should avoid the use of strong acids which can cause two major inconveniences:

Reduction of the cation exchange capacity (CEC) of the clay $[14,15]$.

During the activation process, the effluents generated cannot be easily eliminated.

The ammonium chloride, which is a weak acid, may decomposes under the action of heat and release ammonia gas that shifts the equilibrium to the formation of hydrochloric acid in low concentration [16,17]. This decomposition, catalyzed in the presence of water, is almost total around $350^{\circ} \mathrm{C}$ [17]. The formed protons are responsible to the dissolution of crystalline carbonates impurities and also the attack of the octahedral layered alumina backbone that vulnerable to the strong acids. Consequently, the specific surface area and porosity of this material increase together with the increment in number of acid sites on the surfaces. These properties are accounted for the best adsorption properties of the material $[14,16,18,19]$. It is important to 
note that the chloride ions did not bring any changes to the specific surface seeing that they did not attack the backbone of this material [20].

In a previous study [16], we had shown that the use of strong acids instead of ammonium chloride solution allows the control of the evolution kinetic of the exchange capacity and specific surface area of bentonite. Also, the use of the impregnation technique followed by a heating in the oven has increased the temperature of activation and meanwhile, reduced the heating duration, giving a very efficient material for the bleaching of crude edible oil [21].

In order to extend the range of applications of this new activation technique, we have attempted to study the adsorption of copper (II) ions on bentonite processed with this activation method. The objective of this work is to study the optimal conditions of activation of bentonite after its impregnation in a molar solution of $\mathrm{NH} 4 \mathrm{Cl}$ by heating them in a muffle oven and investigate of the kinetic and thermodynamic phenomena governing the mechanism of the removal of copper (II) ions present in aqueous solutions.

\section{Experimental}

\subsection{Material}

The raw bentonite $(\mathrm{BN})$ used in this study was gracefully offered to us by Bental society (Algeria). BN was collected from Maghnia region (west of Algeria). Its chemical composition is given in the Table 1. The cation exchange capacity (CEC) of raw bentonite was measured using the methylene blue and the capacity was 23.3 mmole. $100 \mathrm{~g}-1$ [22]. All chemicals are analytical grade RP. The copper (II) solutions were prepared by dissolving $\mathrm{CuNO} 3$ in distilled water. The $\mathrm{pH}$ of these solutions was measured by a $\mathrm{pH}$ meter Schott CG711 equipped with a combined glass electrode. The heating of bentonite samples was carried out in a muffle oven (Nabertherm D-2804) consisting of a temperature control system $\left(\operatorname{Tmax}=1200{ }^{\circ} \mathrm{C}\right)$. The analyses of $\mathrm{Cu} 2+$ were recorded on atomic absorption spectrophotometer (SP9 Pye Unicam) with flame generated by airacetylene and a copper lamp, fixed at wavelength $\lambda=324.8$ $\mathrm{nm}$.

Table 1. Chemical composition of raw bentonite (BN) (Bental source).

ComponentSiO $\mathrm{Al}_{2} \mathrm{O}_{3} \mathrm{CaOMgONa}_{2} \mathrm{OK}_{2} \mathrm{O} \mathrm{Fe}_{2} \mathrm{O}_{3} \mathrm{MnOTiO}_{2}$ P. F. Total

\begin{tabular}{llllllllllll}
\hline mass & 57.8 & 19.7 & 1.6 & 3.56 & 1.5 & 1.26 & 2.1 & 0.04 & 0.13 & 12.299 .9
\end{tabular}

\subsection{Methods}

\subsubsection{Characterization of the Porous Texture of Raw Bentonite}

The porous texture of bentonite was characterized by using Micromeritics ASAP2010 for nitrogen gas adsorption analysis at $77 \mathrm{~K}$. This step was achieved after degasification of the clay samples under continuous vacuum for twelve hours at $160{ }^{\circ} \mathrm{C}$. The BET equation was developed in the relative pressures ranging between 0.039 and 0.200 . The results of the relative pressure based on the volume of nitrogen adsorbed allowed us to calculate various parameters of texture (Table 2) by using the BET (BrunauerEmmet-Teller) and BJH (Barret-Joyner-Halenda) equations.

Table 2. Porous texture of raw bentonite $(B N)$.

\begin{tabular}{lllllll}
\hline $\begin{array}{l}\text { Para- } \\
\text { meters }\end{array}$ & $\begin{array}{l}\mathbf{S}_{\mathbf{S}} \\
\left(\mathbf{m}^{\mathbf{2}} \mathbf{g}^{-1}\right)\end{array}$ & $\begin{array}{l}\mathbf{V}_{\mathbf{P}} \\
\left(\mathbf{c m}^{3} \mathbf{g}^{-1}\right)\end{array}$ & $\begin{array}{l}\mathbf{S}_{\mathbf{P}} \\
\left(\mathbf{c m}^{2} \mathbf{g}^{-1}\right)\end{array}$ & $\begin{array}{l}\mathbf{D}_{\mathbf{P}} \\
\left(\mathbf{A}^{\circ}\right)\end{array}$ & $\begin{array}{l}\mathbf{V}_{\text {mic }} \\
\left(\mathbf{c m}^{\mathbf{3}} \mathbf{g}^{-1}\right)\end{array}$ & $\begin{array}{l}\mathbf{S}_{\text {mic }} \\
\left(\mathbf{c m}^{2} \mathbf{g}^{-1}\right)\end{array}$ \\
\hline Value & 57.9 & 0.11 & 99.2 & 60.8 & 0.004 & 9.34 \\
\hline
\end{tabular}

$S_{S}$ : specific surface area; $V_{P}$ : pore volume; $S_{P}$ : pore surface ; $D_{P}$ : pore diameter;

$V_{\text {mic }}$ : micropore volume $; S_{\text {mic }}$ : micropore surface.

\subsubsection{Thermal Treatment of Bentonite Impregnated by $\mathrm{NH}_{4} \mathrm{Cl}$ (1M)}

The raw bentonite was crushed and sieved several times over $50 \mu \mathrm{m}$ screen. This no-treated solid was noted as BN. A part of this pre-treatment $\mathrm{BN}$ was impregnated into $1 \mathrm{M}$ $\mathrm{NH}_{4} \mathrm{Cl}$ solutions with the bentonite $/ \mathrm{NH}_{4} \mathrm{Cl}$ solutions ratio of $1: 1 \mathrm{w} / \mathrm{w}$. The suspension was left overnight at the ambient temperature under constant stirring, then dried in an oven at $60{ }^{\circ} \mathrm{C}$ for several days without washing. The dried material, after a fine crushing, was put in porcelain crucibles and heated in a furnace with controlled temperature values ranging between 100 and $500^{\circ} \mathrm{C}$ at fixed period of times. The $\mathrm{BN}$ clay samples, heated at $100^{\circ} \mathrm{C}$, were placed in the furnace for the different exposition times: $0.5 ; 1 ; 2 ; 3$; 4; 5 and 6 hours. This operation was repeated, in the same manner at 200, 250, 300, 350, 400, 450 and $500{ }^{\circ} \mathrm{C}$. After cooling, each bentonite sample was washed with distilled water until all chloride ions were removed (confirmed with silver nitrate test). These materials were crushed and sieved over $0.05 \mathrm{~mm}$ screen. The bentonite obtained was noted as $\mathrm{BA}$ and used to investigate its $\mathrm{Cu}^{2+}$ removal ability.

\subsubsection{Removal of Copper (II) by Bentonite}

In a $250 \mathrm{~mL}$ polyethylene bottles, a mass of $\mathrm{m}(\mathrm{g})$ activated bentonite $(\mathrm{BA})$ or raw bentonite $(\mathrm{BN})$ was dispersed into $100 \mathrm{~mL}$ of copper solution with initial concentration $\mathrm{C}_{0}\left(\mathrm{mg} \mathrm{L}^{-1}\right)$. The $\mathrm{pH}$ of suspensions varies between 5.5 and 6 (natural $\mathrm{pH}$ of suspensions). The suspensions were centrifuged after continuous stirring and the concentration of $\mathrm{Cu}^{2+}$ at the equilibrium state, $\mathrm{Ce}\left(\mathrm{mg} \mathrm{L}^{-1}\right)$, where the supernatant was measured, was obtained.

\subsubsection{Effect of the Physicochemical Parameters}

The determination of optimum experimental conditions, for bentonite treatment and metal removal, were systematically through the study of following parameters:

Temperature and duration of heating in oven.

Contact time of bentonite-copper (II) solution mixture.

The effect of clay titration ( $\mathrm{g}$ bentonite / $100 \mathrm{~mL}$ copper 
(II) solution).

Temperature influence on the adsorption of copper (II) ions

\section{Results and Discussions}

\subsection{Effect of the Temperature and Heating Times}

$0.2 \mathrm{~g}$ bentonite (BN or BA) was introduced into a polyethylene bottle containing $100 \mathrm{~mL}$ of aqueous solution of $\mathrm{Cu}^{2+}$ with an initial concentration, $\mathrm{C}_{\mathrm{o}}$ of $50 \mathrm{mg} \mathrm{L}^{-1}$. The suspensions were maintained under constant stirring at room temperature overnight. The supernatant of each bottle was analyzed and the results were represented on the Fig. 1.

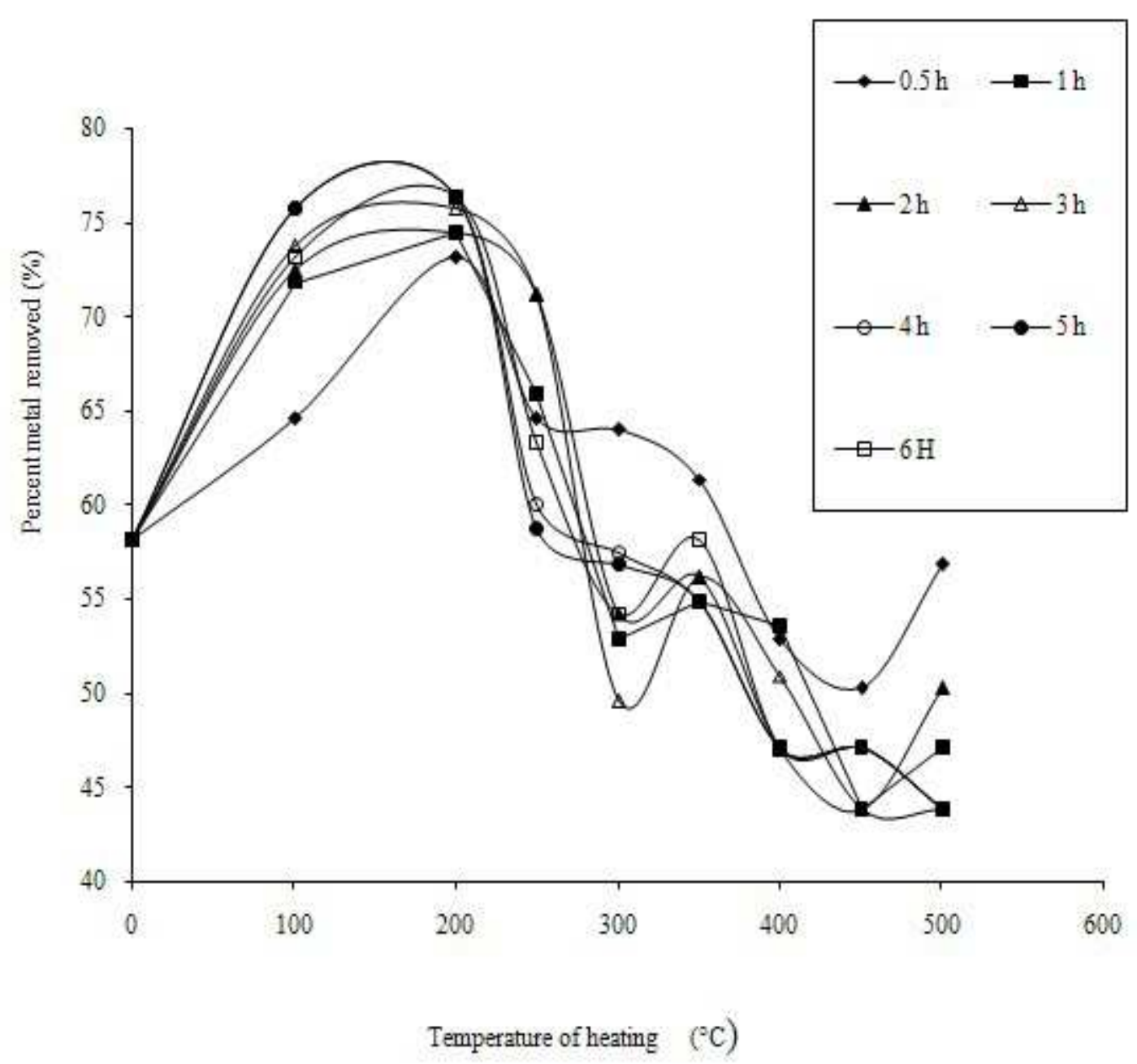

Figure 1. Effect of the temperature $\left({ }^{\circ} \mathrm{C}\right)$ and heating duration $(\mathrm{h})$ on the removal efficiency of Copper $(\%)$ from aqueous solution.

Raw bentonite $\mathrm{BN}$ (non- heated), possesses adsorption properties towards elimination of copper (II) ions from its aqueous solutions. The $\mathrm{Cu}^{2+}$ removal efficiency of $\mathrm{BN}$ was approximately $58 \%$. The curves of Fig. 1 show two distinct shapes, before and after the heating at $200{ }^{\circ} \mathrm{C}$ respectively. Below $200{ }^{\circ} \mathrm{C}$, the removal efficiency of this material increases with as heating temperatures of bentonite increases. This can be explained as the result of increasing specific surface area that inducing an increment in number of adsorption sites [11]. When this material is heated at temperature higher than $200{ }^{\circ} \mathrm{C}$, corresponding to the second shape, it loses more and more its adsorption properties.

It was literately reported that $\mathrm{Cu}^{2+}$ ions exist in diverse cation forms, such as $\mathrm{Cu}(\mathrm{OH})^{+}$and of $\mathrm{Cu}_{2}(\mathrm{OH})_{2}{ }^{2+}$, when the $\mathrm{pH}$ of reaction medium near to $6[6,10,11,23]$. The reaction of decomposition of $\mathrm{NH}_{4} \mathrm{Cl}$ by heating between $100{ }^{\circ} \mathrm{C}$ and $200{ }^{\circ} \mathrm{C}$ produces protons that are sufficient to dissolve the mineral elements of the clay structure which is vulnerable to acid attack. This causes the formation of significant mesoporosity in the clay. It must also be noted that the water molecules adsorbed in the interlayer space of bentonite begins to desorb at $200{ }^{\circ} \mathrm{C}$. The combination of both of these factors agrees with the creation of new Lewis and Bronsted acid sites that are responsible for the adsorption phenomena $[10,11]$. These factors increase the ion exchange capacity of BA induce a real improvement in the absorption properties of this material.

When the temperature is fixed at above $200{ }^{\circ} \mathrm{C}$, the decomposition kinetic of $\mathrm{NH}_{4} \mathrm{Cl}$ is accelerated by the forma- 
tion of strong acidity and meanwhile, causing the destruction of adsorption sites $[11,16]$. Consequently, this directly reduces the $\mathrm{Cu}^{2+}$ ions removal capacity of bentonite $[10,11,23]$.

It is also important to note that when heating the $\mathrm{NH}_{4} \mathrm{Cl}$ impregnated material at temperature below $200{ }^{\circ} \mathrm{C}$ the number of adsorption increased significantly whereas destruction of the same sites was noted at temperature higher than $200{ }^{\circ} \mathrm{C}$. This behavior suggested us to fix the working temperature strictly at $200{ }^{\circ} \mathrm{C}$ for one hour for the continuation of this study.

\subsection{Effect of Contact Time Bentonite - Solution of Cop- $\operatorname{per}($ II)}

$0.2 \mathrm{~g}$ bentonite (BN or $\mathrm{BA})$ was added to $100 \mathrm{~mL}$ of $\mathrm{Cu}^{2+}$ aqueous solution $\left(\mathrm{C}_{\mathrm{o}}=50 \mathrm{mg} \mathrm{L}^{-1}\right)$ to form a suspension. This suspension is maintained under constant stirring at room temperature for a fixed period of times [10-250 $\mathrm{min}]$. The supernatant is then analyzed by spectrophotometer atomic adsorption at $324.8 \mathrm{~nm}$, and the results obtained are represented in the Fig. 2.

The shapes of the curves in Fig. 2 show that the rate of elimination of $\mathrm{Cu}^{2+}$ increases rapidly until it reached an equilibrium state after $45 \mathrm{~min}$. The maximum values reached $62 \%$ for a non-treated bentonite $(\mathrm{BN})$ and $69 \%$ for an activated bentonite (BA) (as shown in Fig 2). However, according to Fig 1, the $\mathrm{Cu}^{2+}$ removal efficiency by raw bentonite $\mathrm{BN}$ is approximately $58 \%$ overnight.

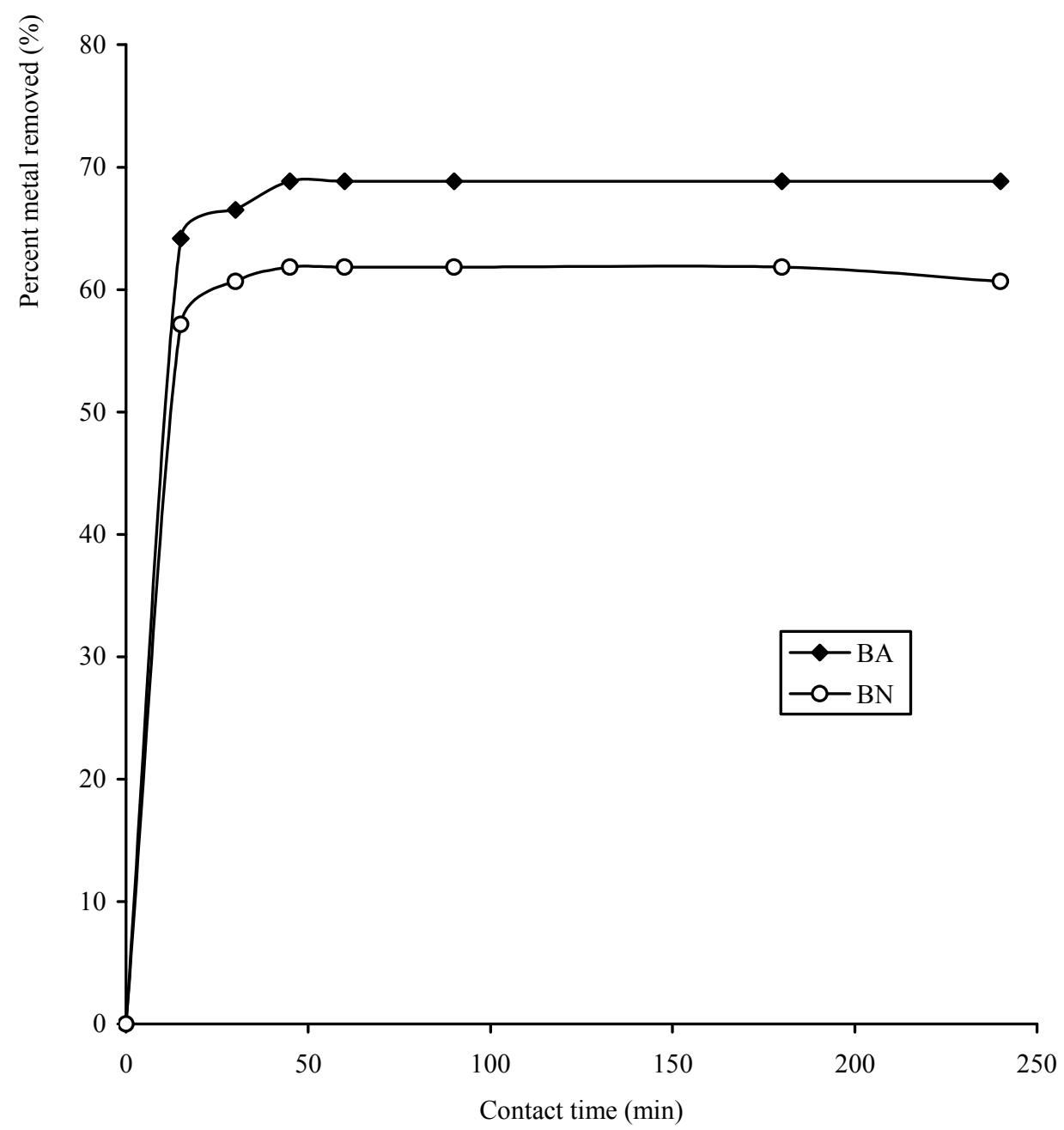

Figure 2. Effect of contact time on the efficiency of copper (II) removal by bentonite.

In order to improve the accuracy of results, the contact time of bentonite-copper (II) solution was set at $120 \mathrm{~min}$.

\subsection{Effect of Clay Dosage}

A mass $\mathrm{m}(\mathrm{g})$ ( $\mathrm{m}$ ranging between 0.1 and $0.6 \mathrm{~g}$ ) of bentonite was added to $100 \mathrm{~mL}$ of aqueous solutions of copper (II) ions that the initial concentration, $\mathrm{C}_{0}=50 \mathrm{mg} \mathrm{L}^{-1}$ and the suspensions was maintained under constant stirring at room temperature for $120 \mathrm{~min}$. The results obtained are summarized in Fig. 3.

The curves of Fig. 3 show that the maximum removal efficiency of $\mathrm{Cu}^{2+}$ by $\mathrm{BN}$ is $74.6 \%$. This percentage of $\mathrm{Cu}^{2+}$ removed was significantly increased to $90 \%$ by a simple thermal treatment of the same material (BN). These maxi- 
mum values of rate were obtained when the dosage of bentonite (either $\mathrm{BN}$ or $\mathrm{BA}$ ) is $0.4 \mathrm{~g} / 100 \mathrm{~mL}$. Beyond this ratio, the curves reach a level in which the quantity of $\mathrm{Cu}^{2+}$ adsorbed remains constant. Thus, it can be concluded that the activation of bentonite is able to improve the removal rate of copper (II) ions.

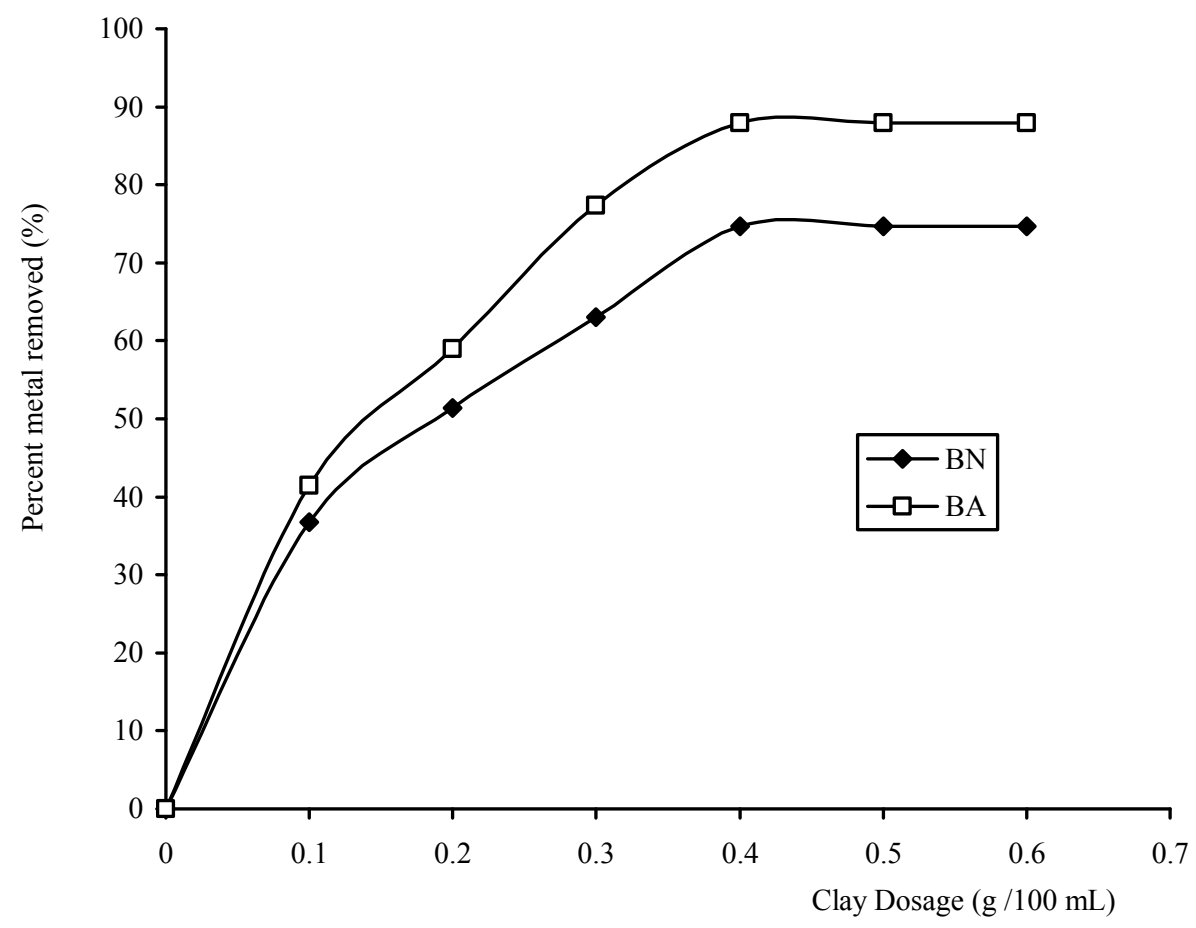

Figure 3. Effect of clay dosage $(\mathrm{g} / 100 \mathrm{ml})$ on removal efficiency (\%) of Cu (II)

\subsection{Adsorption Isotherms}

The adsorption isotherms are, in general very significant in describing the phenomena of different interactions existing at the solid - solution interface. Nevertheless, the reaction mechanism in aqueous solution seems to be very complicated. The adsorption phenomenon is always correlated with theoretical equations which can be described by isotherms as shown by equations below [11,12,23,24].

Freundlich isotherm is used as the model to describe the adsorption on heterogeneous surfaces [23]. This isotherm can be expressed by the following equation:

$$
\frac{X}{m}=K \quad C \frac{\frac{1}{n}}{e^{n}}
$$

Whereas, $\mathrm{C}_{\mathrm{e}}$ is the equilibrium concentration of the solution $\left(\mathrm{mg} \mathrm{L}^{-1}\right), \mathrm{X} / \mathrm{m}$ is amount of adsorbed copper (II) ions per unit of clay mass $\left(\mathrm{mg} \mathrm{g}^{-1}\right), \mathrm{K}$ is Freundlich constant and $1 / \mathrm{n}$ represents the adsorption intensity. This equation was linearized as following:

$$
\log \frac{X}{m}=\log K+\frac{1}{n} \log C_{e}
$$

The curve representing $\log \mathrm{X} / \mathrm{m}$ agains $\log \mathrm{Ce}$ allows us to calculate the parameters of Freundlich isotherms. Thus, the results obtained are shown in Table 3.
Table 3. Parameters of Langmuir, Freundlich and Dubinin-Radushkevich

\begin{tabular}{|c|c|c|c|c|c|c|c|c|c|}
\hline \multirow{2}{*}{$\begin{array}{l}\text { Bentoni } \\
\text { te }\end{array}$} & \multicolumn{3}{|c|}{ Langmuir } & \multicolumn{2}{|c|}{ Freundlich } & \multicolumn{4}{|c|}{ Dubinin-Radushkevich } \\
\hline & $\begin{array}{l}b \\
\mathrm{dm}^{3} \mathrm{~g}^{-1}\end{array}$ & $\begin{array}{c}\mathrm{Q}^{\circ} \\
-1 \\
\mathbf{1} \\
\mathbf{1}\end{array}$ & le $\mathbf{g}_{2}^{r} R_{L}$ & $R_{L} n$ & k $\quad \mathbf{r}^{2}$ & $\begin{array}{l}\boldsymbol{\beta} \\
\mathbf{m o l}^{2} \mathbf{J}\end{array}$ & $\begin{array}{c}\mathrm{q}_{\mathrm{DR}} \\
\mathrm{J}_{1}^{-} \mathrm{mmol} \mathrm{g}^{-}\end{array}$ & $r^{2}$ & $\begin{array}{l}\mathbf{E} \\
\mathrm{kJ} \mathrm{mol} \\
1\end{array}$ \\
\hline BN & 0.04 & 0.12 & 0.980 & 0.321 .5 & 50.460 .99 & $9510^{-9}$ & 0.21 & 0.98 & 810 \\
\hline BA & 0.31 & 0.18 & 0.990 & 0.043 .2 & 23.740 .98 & $8210^{-9}$ & 0.57 & 0.98 & 815.8 \\
\hline
\end{tabular}
isotherms.

Langmuir isotherm model describe the systems that having a simple monolayer adsorbed on the surface. This model has supposed that the adsorption takes place at a specific adsorption sites. The interaction forces between molecules and adsorption sites decreased as these molecules become further from the same surfaces [23]. So, Langmuir isotherm can be defined according to the following equations:

$$
\frac{X}{m}=\frac{Q_{o} \quad b \quad C_{e}}{1+b \quad C_{e}}
$$

While $\mathrm{Q}_{0}$ is the monolayer capacity $(\mathrm{mg} / \mathrm{g})$ and $\mathrm{b}$ is the equilibrium constant $\left(\mathrm{dm}^{3} \mathrm{~g}^{-1}\right)$.

$$
\frac{C_{e}}{\frac{X}{m}}=\frac{1}{Q_{0} b}+\frac{C_{e}}{Q_{0}}
$$


The curve representing $\mathrm{Ce} / \mathrm{X} / \mathrm{m}$ versus Ce allows calculating the parameters of Langmuir isotherms. The results obtained are shown in Table 3.

The main characteristic of the Langmuir equation is the dimensionless constant called equilibrium parameter, $\mathrm{R}_{\mathrm{L}}$ [5]. The Parameter gives information on the type of equilibrium which takes place between two phases (eg. liquidsolid). The $\mathrm{R}_{\mathrm{L}}$ can be expressed by equation (5):

$$
\mathrm{R}_{\mathrm{L}}=\frac{1}{1+b C_{o}}
$$

The $\mathrm{C}_{\mathrm{o}}$ is the highest initial concentration $\left(\mathrm{mg} \mathrm{L}^{-1}\right)$. The value of $\mathrm{R}_{\mathrm{L}}$ indicates that the type of isotherm is: irreversible $\left(\mathrm{R}_{\mathrm{L}}=0\right)$, favorable $\left(0<\mathrm{R}_{\mathrm{L}}<1\right)$, unfavorable $\left(\mathrm{R}_{\mathrm{L}}>1\right)$ or linear $\left(R_{L}=1\right)$. In this study, the results (see Table 3 ) of $\mathrm{R}_{\mathrm{L}}$ show that adsorption on both $\mathrm{BN}$ and $\mathrm{BA}$ surface are favorable.

Langmuir and Freundlich isotherms appear to be insufficient to express all the physical and chemical characteristics of the adsorption. The Dubinin-Radushkevich (D-R) isotherm is commonly used to study the adsorption of metallic ions on clay materials [24]. The D-R isotherm is expressed by the following equation:

$$
\frac{X}{m}=q_{D R}\left[\exp \left(-\beta \varepsilon^{2}\right)\right]
$$

Where $\mathrm{X} / \mathrm{m}$ is the amount of heavy metal that was removed per mass unit of clay (mg/g), $\mathrm{q}_{\mathrm{DR}}$ is the D-R adsorption capacity $(\mathrm{mg} / \mathrm{g}), \varepsilon$ is the Polanyi potential which is related to the concentration at the equilibrium state and expressed by equation (7) .

$$
\mathcal{E}=\mathrm{RT} \ln \left(1+\frac{1}{C e}\right)
$$

Where $\mathrm{R}$ is the constant $\left(\mathrm{kJ} \mathrm{K}^{-1} \mathrm{~mol}^{-1}\right)$ of perfect gases and $\mathrm{T}$ the absolute temperature $(\mathrm{K}), \beta$ is the constant related to the adsorption energy $E$. The main energy of adsorption is calculated by using $E=(2 \beta)^{-1 / 2}$ where, $E$ gives information about the physical and chemical features of the adsorption. The numerical value of sorption energy varies in the range of $1.00-8.00$ and $9.00-16.00 \mathrm{~kJ} \mathrm{~mol}^{-1}$, for physical and chemical adsorption respectively. For some authors, the adsorption energy of an ion-exchange mechanism is within the range of $9-16 \mathrm{~kJ} \mathrm{~mol}^{-1}$ [5]. However the equation of $\mathrm{D}-\mathrm{R}$ can give an estimation for the maximum capacity of adsorption by a solid-solution system. Its expression is given by the linearization of the following equation:

$$
\ln \frac{X}{m}=\ln q_{D R}-\beta \varepsilon^{2}
$$

The curve representing $\ln \mathrm{X} / \mathrm{m}$ versus $\varepsilon^{2}$ allows us to calculate the D-R parameters. So, the results obtained are gathered in Table 3 .

The study of the isotherms of Freundlich, Langmuir and
Dubinin-Radushkevich was carried out using suspensions of $0.4 \mathrm{~g}$ bentonite in $100 \mathrm{~mL}$ of solutions. The initial concentrations vary between 15 and $70 \mathrm{mg} / \mathrm{L}$ of $\mathrm{Cu}^{2+}$. These suspensions were maintained at room temperature under constant stirring for $120 \mathrm{~min}$. The results obtained for the three isotherms studied are given in Table 3.

The examination of the results given in Table 3 shows a sharp increase in the parameters of Freundlich and Langmuir after thermal treatment of the bentonite.

After treating at $200{ }^{\circ} \mathrm{C}$ for one hour, the molecular monolayer of Langmuir and their adsorption capacities have

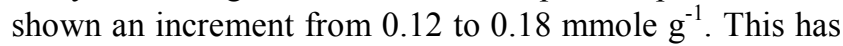
caused an increase in the adsorption capacity of BN without reaching its CEC value of $0.23 \mathrm{mg} / \mathrm{g}$. This behavior is in agreement with the mechanism involving the copper (II) adsorption thru cationic exchange [11]. The dissolution of the mineral substances under the effect of strong acidity implies a high level of division of clay that allows the access to more exchange sites this leads to an improvement of exchange capacity [16]. In connection to this, it must also be noted that additional effect of hydrochloride acid, resulting from the decomposition of $\mathrm{NH}_{4} \mathrm{Cl}$ at $200{ }^{\circ} \mathrm{C}$, which cannot be excluded. During the decomposition process, the edges of clay sheets could be opened to increase its surface area and pores diameter [11].

The values of $\mathrm{R}_{\mathrm{L}}$ constitute a good illustration for a favorable adsorption of copper (II) ions by this bentonite. Moreover the $R_{L}$ value of $B A$ is close to zero (0.04), indicating that the adsorption phenomenon is spontaneously produced $[11,25]$.

It was noted that the Freundlich parameters increase as expressed by the constant $\mathrm{K}$ and $\mathrm{n}$, which increased from 0.46 to 3.74 and 1.51 to 3.21 , respectively. The adsorption intensity given by the Freundlich coefficient $(1 / \mathrm{n})$ is smaller than the unity: these values are 0.66 and 0.31 for $\mathrm{BN}$ and $\mathrm{BA}$ respectively. These results indicate that the adsorption of $\mathrm{Cu}^{2+}$ onto the bentonite samples under the studied experimental conditions is favorable, confirming the previously mentioned conclusions about $\mathrm{R}_{\mathrm{L}}$ parameter [26].

However, the Dubinin-Radushkevich (D-R) isotherm results obtained have shown that energy, E varies from $10 \mathrm{~kJ}$ mole ${ }^{-1}$ to $15.8 \mathrm{~kJ}$ mole ${ }^{-1}$. These values are compatible with the mechanism of elimination of copper (II) ions by bentonite thru ionic exchange process as reported in the literature $[5,24,25]$

\subsection{Adsorption Kinetics}

Two models were used to interpret the experimental results obtained during the examination of the adsorption kinetic of copper (II) ions onto the bentonite, that is, the pseudo-first-order and the pseudo-second-order models [10-12,23,27,28].

The adsorption rate constant proposed by Lagergren and Ho [29] obeys the first order reaction kinetic as expressed by the following linearized equation: 


$$
\log \left(q_{e}-q_{t}\right)=\log q_{e}-\frac{k_{1}}{2,303} t
$$

Where $\mathrm{k}_{1}$ is the first order adsorption rate constant ( $\mathrm{min}^{-}$ $\left.{ }^{1}\right), q_{t}$ is the amount of heavy metal adsorbed at time $\mathrm{t}(\mathrm{mg} / \mathrm{g})$ and $\mathrm{q}_{\mathrm{e}}$ is the amount of heavy metal adsorbed at saturation (mg/g).

The kinetic model of the second order adsorption reaction [28] can be expressed by the following linearized equation:

$$
\frac{t}{q_{t}}=\frac{1}{k_{2} q_{e}^{2}}+\frac{1}{q_{e}} t
$$

Where $\mathrm{k}_{2}$ is the second order reaction constant, $\mathrm{q}_{\mathrm{e}}$ is the amount of heavy metal adsorbed at saturation $(\mathrm{mg} / \mathrm{g})$.

In order to calculate the adsorption rate constants of copper removal, the first order kinetic was applied. The curves representing $\log \left(\mathrm{q}_{\mathrm{e}}-\mathrm{q}_{\mathrm{t}}\right)$ versus $\mathrm{t}$ did not shown any linearity for both $\mathrm{BN}$ and $\mathrm{BA}$ samples. Meanwhile, the pseudo-second-order kinetic, when it was applied for the same samples, the curves plotted $t / q_{t}$ against $t$ are, here, rather linear. Thus, the rate constants $\mathrm{k}_{2}$ can be calculated from the slope of these curves (Fig. 4). The values of $\mathrm{q}_{\mathrm{e}}$, were calculated for the both samples from the intersection of the straight line of the second order kinetic curves with the ordinates (y-axis) (See Table 4).

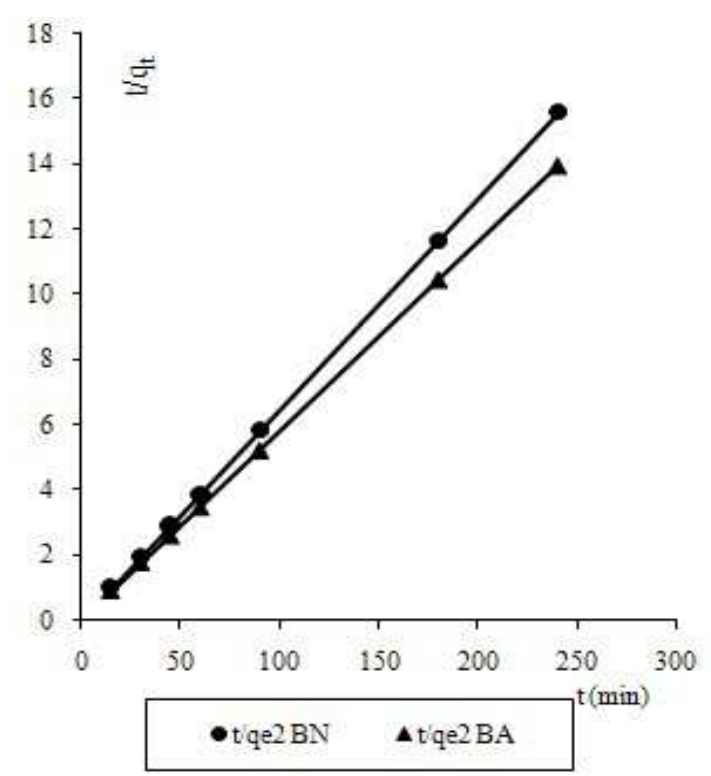

Figure 4. Pseudo-second-order reaction kinetics for the adsorption of copper ions by bentonite.

The results given in Table 4 shows that the values of qe, calculated and qe, experimental are equal. Moreover, all the correlation coefficients of second order kinetic are exalted, suggesting a high compatibility of this model with the removal of copper (II) ions by bentonite. The values of qe, given in Table 4, have shown that the thermal can improve the removal efficiency of copper (II) ions.
Table 4. Parameters of second order kinetic of removal copper by bento-

\begin{tabular}{|c|c|c|c|c|}
\hline $\begin{array}{l}\text { Para- } \\
\text { meters }\end{array}$ & $\begin{array}{l}q_{e, \text { experimental }} \\
\left(\text { mmole } g^{-1}\right)\end{array}$ & $\begin{array}{l}\mathrm{K}_{2} \\
(\mathrm{~g} \\
\left.\mathrm{mmole}^{-1} \mathrm{mn}^{-1}\right)\end{array}$ & 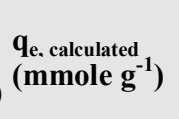 & $\mathbf{r}^{2}$ \\
\hline BN & 243.3 & 0.145 & 243.77 & 0.99 \\
\hline BA & 271.02 & 0.089 & 271.98 & 1 \\
\hline
\end{tabular}
nite

The examination of the results given in Table 4 shows that the values of $\mathrm{q}_{\mathrm{e}}$,calculated and $\mathrm{q}_{\mathrm{e}}$, experimental are equal. Moreover, all the correlation coefficients of second order kinetic are exalted suggesting a high compatibility with the second order model governing the removal copper ions by bentonite. The values of qe, given in Table 4, show that the thermal treatment expresses an improvement in the removal efficiency of copper ions.

\subsection{Thermodynamic Study}

The thermodynamic parameters of the adsorption process as enthalpy $\left(\Delta \mathrm{H}^{\mathrm{o}}, \mathrm{kJ} \mathrm{mol}^{-1}\right)$, entropy $\left(\Delta \mathrm{S}^{\mathrm{o}}, \mathrm{J} \mathrm{K}^{-1}\right.$ $\left.\mathrm{mol}^{-1}\right)$ and Gibbs free energy $\left(\Delta \mathrm{G}^{\mathrm{o}}, \mathrm{kJ} \mathrm{mol}^{-1}\right)$ are estimated using the following equations:

$$
\begin{gathered}
\Delta G^{0}=-\mathrm{RT} \ln \mathrm{K}_{\mathrm{d}} \\
\ln K_{d}=\frac{\Delta S^{0}}{R}-\frac{\Delta H^{0}}{R T}
\end{gathered}
$$

Where $K_{d}$ is the distribution coefficient of the adsorption sites on the adsorbate, $\mathrm{T}$ absolute temperature and $\mathrm{R}$ is perfect gases constant. The plot $\ln K_{d}$ against $1 / T$ should be linear with the slope $\left(-\Delta \mathrm{H}^{\mathrm{o}} / \mathrm{R}\right)$ and its intersection with ordinate (y-axis) will give rise to $\Delta \mathrm{S}^{\mathrm{O}} / \mathrm{R}, \Delta \mathrm{H}^{\mathrm{o}}$ and $\Delta \mathrm{S}^{\mathrm{o}}$ values. In this case, it seems to be important to note that the free energy of Gibbs $\Delta \mathrm{G}^{\mathrm{o}}$ constitutes the fundamental criterion of the adsorption spontaneity.

The copper ions removal efficiency ( $\%$ rate) by these materials ( $\mathrm{BN}$ or $\mathrm{BA}$ ) can be deduced from $\mathrm{K}_{\mathrm{d}}$ values using the following relation:

$$
\% \text { rate }=\frac{100 K_{d}}{K_{d}+\frac{V}{m}}
$$

Where $\mathrm{V}$ is the volume of solution $(\mathrm{mL})$ and $\mathrm{m}$ is mass of clay $(\mathrm{g})$.

The $\mathrm{Cu}^{2+}$ removal rate percentage have been calculated for solutions maintained at constant temperatures of 25,35 and $45{ }^{\circ} \mathrm{C}$ using suspensions with initial concentration of 15,25 and $35 \mathrm{mg} \mathrm{L}^{-1}$. These suspensions were constantly stirred for $120 \mathrm{~min}$. The Gibbs free energy $\Delta G^{0}$ is calculated using the following thermodynamic equation:

$$
\Delta G^{0}=\Delta H^{0}-\mathrm{T} \Delta S^{0}
$$


The obtained results were given in Table 6 . The values of $\mathrm{K}_{\mathrm{d}}$ vary from 42.2 to 230.8 for $\mathrm{BN}$ and from 1000.44 to 3916.67 for BA. The removal rate of copper ions varies from 47.4 to $49.7 \%$ for BN and from 81.8 to $94 \%$ for BA. We can conclude that the thermal treatment has exalted the $\mathrm{K}_{\mathrm{d}}$ values and therefore the removal rates of copper ions.

However, when the activated bentonite BA is used, there are no significant variations in the $K_{d}$ values and in the removal rates for copper ions in spite of the rising of the temperature for the $\mathrm{Cu}^{2+}$ aqueous solutions. So, it seems possible to deduce that there is no significant influence of the temperature on the adsorption process of copper ions by BA material in the range of the temperatures investigated. This, do not allow us to calculate the thermodynamic parameters. In this case, it is probably possible to think to an establishment of a spontaneous equilibrium at the contact of copper ions with the surface particles of clay BA. This phenomenon is resulted from the thermal treatment of the bentonite. Thus, the thermal activation of this bentonite has allowed to adsorption phenomena to overcome only a small energetic barrier in the $\mathrm{BN}$ material. This treatment has facilitated the adsorption of $\mathrm{Cu}^{2+}$ ions on the surface of bentonite BA [10-12].

The results given in Fig. 5 were obtained with bentonite $\mathrm{BN}$ and they have shown that, for an initial concentration of $15 \mathrm{mg} \mathrm{L}-1$, no effect was observed for $\mathrm{Kd}$ values (slope zero) whereas for initial concentrations of 25 et $35 \mathrm{mg} \mathrm{L}-1$, an increase of the temperature influences advantageously the $\mathrm{Kd}$ values and removal rates ( $\%$ rate), enable the calculation of the thermodynamic parameters given in following Table 6.

Table 5. Effect of the temperature on the removal rate and $K_{d}$ values.

\begin{tabular}{lllll}
\hline Co $(\mathbf{m g} / \mathbf{l})$ & Temperature $\left({ }^{\circ} \mathbf{C}\right)$ & $\mathbf{2 5}$ & $\mathbf{3 5}$ & $\mathbf{4 5}$ \\
\hline \multirow{4}{*}{15} & Kd(BN) & 225.6 & 230.8 & 225.6 \\
& $\%$ rate. $(\mathrm{BN})$ & 47.4 & 48 & 47.4 \\
& Kd(BA) & 3916.67 & 3916.67 & 3916.67 \\
& $\%$ rate. $(\mathrm{BA})$ & 94 & 94 & 94 \\
& Kd (BN) & 187.0 & 216.4 & 242.1 \\
& \% rate. $(\mathrm{BN})$ & 42.8 & 46.4 & 49.2 \\
& Kd(BA) & 1766.13 & 1770.60 & 1792.09 \\
& \% rate. $(\mathrm{BA})$ & 83.12 & 83.64 & 83.8 \\
& Kd (BN) & 183.2 & 205.7 & 247.2 \\
& \% rate. $(\mathrm{BN})$ & 42.2 & 45.1 & 49.7 \\
& Kd (BA) & 1000.44 & 1036.75 & 1052.56 \\
& $\%$ rate. $(\mathrm{BA})$ & 81.8 & 82.22 & 82.4 \\
\hline
\end{tabular}

The results mentioned in Table 6 show that the initial concentrations 25 and $35 \mathrm{mg} \mathrm{L}^{-1}$ are in agreement with an endothermic adsorption process for the copper ions removal on bentonite seeing that $\Delta H^{0}>0[3,27]$. Also, the positive values of the entropy attest of an affinity between the $\mathrm{Cu}^{2+}$ ions and the clay material $[2,27]$. Thus, the positive entropy favors the complexation and the stability of adsorption. The $\Delta G^{0}$ values (absolute value) increase with the increasing of the temperature have indicated the spontaneity in the adsorption process of $\mathrm{Cu}^{2+}$ ions by bentonite $[3,27]$.

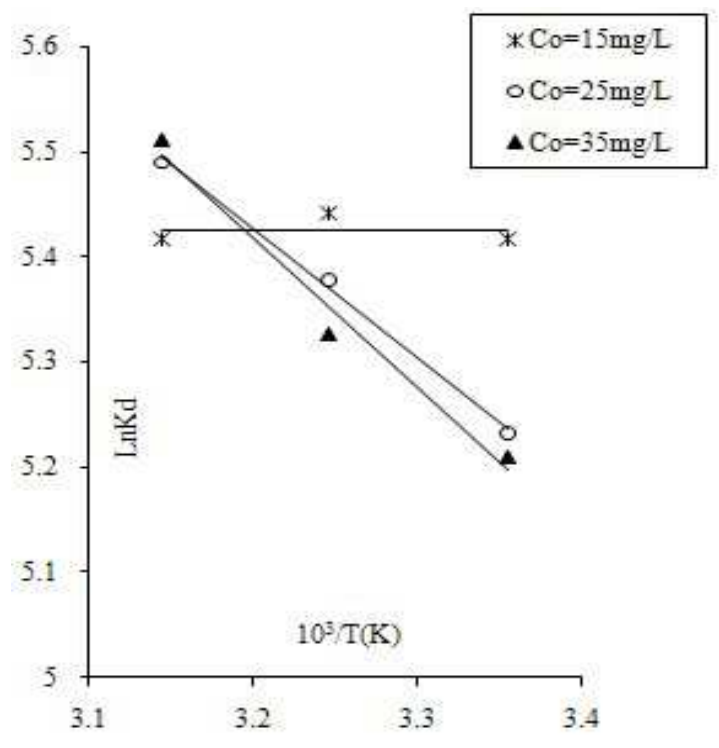

Figure 5. Effect of the temperature on $\mathrm{LnK}_{d}$ versus $10^{3} /$ T for raw bentonite $B N$.

Table 6. Energetic data obtained from thermodynamic parameters of $\mathrm{Cu}^{2+}$ adsorption by $\mathrm{BN}$.

\begin{tabular}{|c|c|c|c|c|c|c|}
\hline \multirow{2}{*}{$\begin{array}{l}\text { Co } \\
\text { (mg l-1) }\end{array}$} & \multirow{2}{*}{$\mathbf{R 2}$} & \multirow{2}{*}{$\begin{array}{l}\triangle H^{0} \\
(\mathrm{KJ} \text { mole1) }\end{array}$} & \multirow{2}{*}{$\begin{array}{l}\triangle S^{0} \\
(\mathrm{~J} / \mathrm{K} \text { mole-1) }\end{array}$} & \multicolumn{3}{|c|}{$-\triangle G^{0}($ KJ mole -1$)$} \\
\hline & & & & 298 & 308 & 318 \\
\hline 25 & 0.99 & 10.17 & 77.63 & 12.96 & 12.96 & 13.74 \\
\hline 35 & 0.97 & 11.77 & 82.67 & 12.87 & 12.87 & 13.69 \\
\hline
\end{tabular}

The results given in Fig.5 are obtained with bentonite $\mathrm{BN}$ and show that, for an initial concentration of $15 \mathrm{mg} \mathrm{l}^{-1}$, anyone effect was observed for $\mathrm{K}_{\mathrm{d}}$ values (slope zero) whereas For initial concentrations of 25 et $35 \mathrm{mg} \mathrm{l}^{-1}$, an increase of the temperature influences advantageously the $\mathrm{K}_{\mathrm{d}}$ values and removal rates (\%rate) rendering enable to calculate the thermodynamic parameters given in following Table 6.

The results mentioned in Table 6 show that the initial concentrations 25 and $35 \mathrm{mg} \mathrm{l}^{-1}$ are in agreement with an endothermic adsorption process for the copper ions removal on bentonite seeing that $\Delta H^{0}>0[3,27]$. Also, the positive values of the entropy attest of an affinity between the $\mathrm{Cu}^{2+}$ ions and the clay material $[2,27]$. Thus, the positive entropy favors the complexation and the stability of adsorption, while the $\Delta G^{0}$ values ( absolute value ) increase with the increasing of the temperature indicating the spontaneousness in the adsorption process of $\mathrm{Cu}^{2+}$ ions by bentonite[3,27]. 


\section{Conclusion}

The heating of raw bentonite impregnated in $1 \mathrm{M}$ ammonium chloride solutions in the oven renders it possibility to create from new sites of ion exchange and this leads to an increase of the adsorption capacity of copper (II) ions from their aqueous solutions with $\mathrm{pH}=6$ using bentonite, obtained from Maghnia (west Algeria). This thermal treatment improves the affinity of this material towards the copper ions adsorption while, a process of a spontaneous equilibrium is established as soon as the contact is made between the copper (II) ions on the surface of clay particles in aqueous solutions. The study of adsorption isotherms shows that the removal efficiency of $\mathrm{Cu}^{2+}$ ions is governed by the two traditional models; Langmuir and Freundlich, with which the adsorption mechanism of $\mathrm{Cu}^{2+}$ ions by bentonite is a phenomenon of ionic exchange. This thermal treatment of bentonite inhibited the temperature effect of the aqueous solutions towards the removal rate of $\mathrm{Cu}^{2+}$ ions and also the improving of the $\mathrm{K}_{\mathrm{d}}$ values. Owing to this new activation technique, applied for the clay materials, a rational use of bentonite could be envisaged in the treatment of wastwaters often polluted by the heavy metals. Thus, this work may be considered as a modest contribution to minimize the quantities of sludge during the decontamination of industrial effluents containing the heavy metals such as the family of copper (II).

\section{References}

[1] F. Fenglian, W. Qi, "Removal of heavy metal ions from wastewaters: a review", J. Environ. Manage. 92, pp.407-418, 2011

[2] P. M. Choksi, V. Y. Joshi,. Adsorption kinetic study for the removal of nickel (II) and aluminum (III) from an aqueous solution by natural adsorbents. Desalination, 208, pp216231, 2007

[3] R. Donat, A. Akdogan, E. Erdem, H. Cetisli,. "Thermodynamics of $\mathrm{Pb} 2+$ and $\mathrm{Ni} 2+$ adsorption onto natural bentonite from aqueous solutions". J. Colloid Interface Sci. 286, pp.43-52, 2005

[4] A. Benhamou, A. Yaacoubi, L.Nibou, B.Tanouti,. Adsorption of metal ions onto Moroccan stevensite : kinetic and isotherm studies. J. Colloid Interface Sci. 282, pp.320-326, 2005

[5] S. H. Lin, R. S. Juang, "Heavy metal removal from water by sorption using surfactant-modified montmorillonite", J. Hazard. Mater. B92, pp.315-326, 2002

[6] Y. S. Ho, A. E. Ofomaja. "Kinetic studies of copper ion adsorption on palm kernel fiber". J. Hazard. Mater., B137, pp.1796-1802, 2006

[7] C. H. Weng, C. Z. Tsai, S. H. Chu, Y. C. Sharma, "Adsorption characteristics of copper (II) onto spent activated clay". Sep. Purif. Technol. 54, pp.187-197, 2007

[8] C. Abdelouhab, H. Ait Amar, T. Z. Obretenov, A. Gaid, "Caractéristiques physico-chimiques et structurales de quel- ques argiles bentonitiques du nord-ouest algérien”, Analusis, 16 (5), pp.292-299, 1988

[9] S. Caillers, S. Henin, M. Rautureau, "Minéralogie des argiles: structure et propriétés physico - chimique", Tome 1, Ed. Masson et INRA, Paris, 1982

[10] K. G. Bhattacharyya, S. G. Susmita,. "Adsorptive accumulation of $\mathrm{Cd}(\mathrm{II}), \mathrm{Co}(\mathrm{II}), \mathrm{Cu}(\mathrm{II}), \mathrm{Pb}(\mathrm{II})$ and $\mathrm{Ni}(\mathrm{II})$ from water on montmorillonite : Influence of acid-activation". J. Colloid Interface Sci., 310, pp.411-424, 2007

[11] K. G. Bhattacharyya, S. G. Susmita, "Influence of acidactivation on adsorption of $\mathrm{Ni}(\mathrm{II})$ and $\mathrm{Cu}(\mathrm{II})$ on kaolinite and montmorillonite : Kinetic and thermodynamic study". Chem. Eng. J. 139 (1), pp.1-13, 2008

[12] K. G. Bhattacharyya, S. G. Susmita, "Removal of Cu(II) by natural and acid-activated clays: An insight of adsorption isotherm, kinetic and thermodynamics", Desalination, 272(1-3), pp.66-75, 2011

[13] S. Ding, Y. Sun, C. Yang, B. Xu, "Removal of copper from aqueous solutions by bentonites and the factors affecting it", Mining Science and Technology, 19, pp.489-492, 2009

[14] G. E. Christidis, P. W. Scott, A. C. Dunham, "Acid activation and bleaching capacity of bentonites from islands of Milos and Chios, Aegean, Greece”, Appl. Clay Sci. 12, pp.329-347, 1997

[15] E. Gonzales-Pradas, M. Villafranca-Sanchez, F. CantonCruz, M.Sosias-Viciana, M. Fernandez-Perez, "Adsorption of cadmium and zinc from aqueous solution on natural and activated bentonite", J. Chem. Tech. Biotechnol. 59, pp.289-295, 1994

[16] A. Boukerroui, M. S. Ouali, "Activation d'une bentonite par un sel d'ammonium: évolution de la capacité d'échange et de la surface spécifique”, Ann. Chim. Sci. Mat., 25, pp.583590,2000

[17] S. Balci, T. Dogu, H. Yucel, "Characterization of activated carbon produced from almond shell and hazelnut shell", J. Chem. Tech. Biotechnol. 60, pp.419-426, 1994

[18] Vengris T., Binkiene R., Eikauskaite A.,. Nickel, copper and zinc removal from waste water by a modified clay sorbent, Appl. Clay Sci. 18, pp.183-190 , 2001

[19] T. Alemdaroglu, G. Akkus, M. Onal, Y. Sarikaya, "Investigation of the surface acidity of a bentonite modified by acid activation and thermal treatment", Turk. J. Chem. 27, pp.675-681, 2003

[20] Z. Sarbak, "Structural and surface properties of anionactivated clay" Materials Chemistry Phys. 39, pp.91-97, 1994

[21] A. Boukerroui, M. S. Ouali, Z. Derriche, "Décoloration d'une huile alimentaire par une bentonite activée au chlorure d'ammonium”, J. Soc. Alg. Chim., 9, pp.237-245, 1999

[22] G. Kahr, F.T. Madsen, "Determination of the cation exchange capacity and the surface area of bentonite, illite and kaolinite by methylen blue adsorption". Appl. Clay Sc. 9, pp.327-336, 1995

[23] S. Veli, B. Alyus, "Adsorption of copper and zinc from aqueous solution by using natural clay" J. Hazard. Mater. 149, pp.226-233, 2007 
[24] C-T. Hsieh, H. Teng, "Langmuir and Dubinin-Radushkevich analyses on equilibrium adsorption of activated carbon fabrics in aqueous solutions", J. Chem. Tech. Biotechnol. 75, pp1066-1072, 2000

[25] A. Ozcan, A. S Ozcan., S. Tunali, T. Akbar, I. Kiran, "Determination of the equilibrium, kinetic and thermodynamic parameters of adsorption of copper (II) ions seeds of Capsicum annuum”, J. Hazard. Mater. B124, pp. 200-208, 2005

[26] E. Eren, B. Afsin,. "An investigation of $\mathrm{Cu}$ (II) adsorption by raw and acid-activated bentonite : A combined potenti- ometric, thermodynamic, XRD, IR, DTA study". J. Hazard. Mater., 151, pp. 682-691, 2008

[27] F. C.Wu, R. L Tseng and R. S. Juang, "Kinetics of colour removal by adsorption from water using activated clay", Environ. Technol., 22, pp721-729, 2001

[28] Y. S.Ho,. "Review of second-order models for adsorption systems", J. Hazard. Mater., B136, pp. 2681-689, 2006

[29] Y. S. Ho, "Citation review of Lagergreen kinetics rate equation on adsorption reaction", Scientometrics 59, pp. 171-177, 2004.. 